\title{
Gender- and region-specific alterations in bone metabolism in Scarb1-null female mice
}

\section{Corine Martineau, Louise Martin-Falstrault ${ }^{1}$, Louise Brissette ${ }^{1}$ and Robert Moreau}

Laboratoire du Métabolisme Osseux, BioMed, Département des Sciences Biologiques Université du Québec à Montréal, Case Postale 8888, Succursale Centre-ville, Montréal, Quebec, Canada H3C 3P8

${ }^{1}$ Laboratoire du Métabolisme des Lipoprotéines, BioMed, Département des Sciences Biologiques, Université du Québec à Montréal, Montréal, Quebec, Canada H3C 3P8
Correspondence should be addressed to R Moreau

Email

moreau.robert@uqam.ca

\begin{abstract}
A positive correlation between plasma levels of $\mathrm{HDL}$ and bone mass has been reported by epidemiological studies. As scavenger receptor class B, type I (SR-BI), the gene product of Scarb1, is known to regulate HDL metabolism, we recently characterized bone metabolism in Scarb1-null mice. These mice display high femoral bone mass associated with enhanced bone formation. As gender differences have been reported in HDL metabolism and SR-BI function, we investigated gender-specific bone alterations in Scarb1-null mice by microtomography and histology. We found $16 \%$ greater relative bone volume and $39 \%$ higher bone formation rate in the vertebrae from 2-month-old Scarb1-null females. No such alteration was seen in males, indicating gender- and region-specific differences in skeletal phenotype. Total and HDL-associated cholesterol levels, as well as ACTH plasma levels, were increased in both Scarb1-null genders, the latter being concurrent to impaired corticosterone response to fasting. Plasma levels of estradiol did not differ between null and WT females, suggesting that the estrogen metabolism alteration is not relevant to the higher vertebral bone mass in female Scarb1-null mice. Constitutively, high plasma levels of leptin along with 2.5 -fold increase in its expression in white adipose tissue were measured in female Scarb1-null mice only. In vitro exposure of bone marrow stromal cells to ACTH and leptin promoted osteoblast differentiation as evidenced by increased gene expression of osterix and collagen type I alpha. Our results suggest that hyperleptinemia may account for the gender-specific high bone mass seen in the vertebrae of female Scarb1-null mice.
\end{abstract}

\author{
Key Words \\ - Scarb1 \\ - SR-BI \\ - high bone mass \\ osteoblasts \\ - leptin \\ - corticosterone \\ - adrenocorticotropin
}

\section{Introduction}

Bone tissue is constantly renewed in a process called remodeling. Remodeling relies on the activities of specialized cells, bone-forming osteoblasts, and bone-resorbing osteoclasts, to maintain bone mass (Clarke 2008). The balance between bone formation and resorption involves the regulation of bone cell activities by several endocrine and paracrine axes including steroid hormones (Frenkel et al. 2010), adrenocorticotropic hormone (ACTH; Isales et al. 2010), and cytokines (Hughes et al. 2006). Uncoupling of the formation and resorption processes results in improper bone mass maintenance. Bone mass results from the difference between peak bone mass, defined as the completion of skeletal growth typically occurring in early adulthood, and age-related bone loss (Rizzoli et al. 2001,

Published by Bioscientifica Ltd. 
Stagi et al. 2013). It is generally accepted that the key determinant in healthy bone is the achievement of a higher peak bone mass, which delays or even prevents the onset of osteoporosis later on in life (Stagi et al. 2013).

Several factors influence peak bone mass, predominantly gender, genetics, and physical activity, as well as vitamin D and calcium intake (Rizzoli et al. 2001, Stagi et al. 2013). It is a well-known fact that men tend to achieve higher peak bone mass than do women, presumably due to the longer period of bone mass gain in the former (Rizzoli et al. 2001). Bone accrual is also site specific within the same skeleton, with preferential bone mineral accumulation in the lumbar vertebrae and femoral neck (Rizzoli et al. 2001, Bonjour et al. 2009); these also happen to be common sites for osteoporotic fractures and show the greatest gender-related dimorphism (Raisz 2005, Bonjour et al. 2009). Several determinants of peak bone mass are common to that of osteoporosis; factors that compromise bone mass are attributed to race, smoking, inactive lifestyle, malnutrition, and underlying metabolic disorders such as diabetes and atherosclerosis are often associated with lower bone mass (Leidig-Bruckner \& Ziegler 2001, Sweet et al. 2009, Stojanovic et al. 2011). Genetic control of bone mass is polygenic and the specific genes involved are beginning to be enumerated, such as genetic variants/mutations of vitamin $\mathrm{D}$ and estrogen receptors (Mitchell \& Yerges-Armstrong 2011). Recent attention has been given to atherogenic conditions with low HDL plasma levels as factors compromising bone health, and numerous associations, have been revealed between lower bone mass and cardiovascular diseases (Banks et al. 1994, Uyama et al. 1997, Barengolts et al. 1998, von der Recke et al. 1999, Hegsted 2001, Yamaguchi et al. 2002, Poli et al. 2003, Adami et al. 2004, Orozco 2004). In accordance, a positive correlation between plasma HDL levels and bone mass has been reported by epidemiological studies (reviewed in Ackert-Bicknell (2012)), suggesting that, in addition to protecting against atherosclerosis, HDL contribute to a healthy environment for bones.

The product of the Scarb1 gene, the scavenger receptor class B, type I (SR-BI) is recognized as a high-affinity HDL receptor (Acton et al. 1996) and is known for its role in HDL metabolism (Cuchel \& Rader 2006). Scarb1-null mice show high HDL-associated cholesterol (HDL-C) levels due to impaired selective uptake of cholesterol by the liver (Rigotti et al. 1997). Also, Scarb1-null male mice exhibit lack of SR-BI-mediated cholesterol uptake from HDL by the adrenal glands and concurrent impaired corticosterone response to stress and high plasma levels of ACTH
(Hoekstra et al. 2008, 2013, Martineau et al. 2014). Given that we reported the expression of SR-BI by osteoblasts (Brodeur et al. 2008), we recently characterized bone metabolism in Scarb1-null mice (Martineau et al. 2014). Higher trabecular bone mass in femora and greater proliferation rate and differentiation of bone marrow mesenchymal stromal cells (MSCs) were found in Scarb1null mice, concurrent to enhanced bone formation. Of interest, differences between male and female Scarb1-null mice were observed in cortical bone volume of the femurs from Scarb1-null female mice which had increased volume compared with WT mice, whereas no difference was noted in males.

Skeleton sexual dimorphism is generally attributed to sex steroids such as estradiol $\left(\mathrm{E}_{2}\right)$, but also to growth hormone, insulin-like growth factor, and mechanical sensitivity to loading (Callewaert et al. 2010). Gender differences in lipoprotein metabolism have also been evidenced (for a review, Knopp et al. (2005)), but it is unknown if and how this affects bone. Of interest, lower levels of SR-BI are found in the liver of female mice (Brodeur et al. 2005) and in accordance, estrogen was shown to reduce hepatic SR-BI expression. In contrast, SR-BI expression in adrenal glands is increased by estrogen (Landschulz et al. 1996) and its expression is enhanced by ACTH (Sun et al. 1999). In addition, the adipokine leptin was shown to stimulate SR-BI expression in hepatocytes (Lundasen et al. 2003). Sex differences in adipose tissue, the main source of leptin, were documented and recently, leptin has been identified as an important direct bone growth modulator (Turner et al. 2013); gender-related differences in regard to effects of leptin on bone were also noted (Thomas et al. 2001). Thus, the observed gender differences in the bone structure of Scarb1-null mice may be related to the estrogen, ACTH, and/or leptin hormonal axes. This study therefore aimed at assessing how Scarb1 deficiency could produce gender-specific skeletal alterations in mice through analysis of vertebral architecture, serology, and marrow-derived stromal cells' response to relevant endocrine factors.

\section{Materials and methods}

\section{Animals}

Scarb1-null mice on a C57BL6/129 background were obtained from Jackson Laboratories (stock no. 003379; Bar Harbor, ME, USA) and crossbred with WT C57BL/6 mice. Owing to their low fertility, Scarb1-null females were fed a $0.5 \%$ probucol diet (Research Diet, New-Brunswick,

Published by Bioscientifica Ltd. 
NJ, USA) for 10 days before mating (Miettinen et al. 2001). The heterozygous (HZ) progeny was mated to obtain first generation (F1) WT and null couples; HZ, WT, and null couples were bred in parallel throughout each generation to allow littermate and inter-litter comparisons, as well as to insure that probucol did not affect the observed phenotype. All animals were kept under a $12 \mathrm{~h}$ light: $12 \mathrm{~h}$ darkness cycle at $25^{\circ} \mathrm{C}$, with free access to food and water, unless specified otherwise. Two- and four-month-old mice from F7-F10 generations were used throughout the study. The mice used for the ACTH/glucocorticoid (GC) study were the same as the ones used by Martineau et al. (2014); animals were added to complete the leptin study and lumbar vertebrae analyses. All experiments were performed according to UQÀM Institutional Animal Care Committee guidelines (\#611). Following euthanasia, whole body, abdominal fat, and uterine weights were determined.

\section{Serology}

Whole blood sample was harvested through cardiac punctures and collected in $3 \mathrm{ml}$ heparinized tubes (68 USP, BD Bioscience, Mississauga, ON, Canada). Plasma was obtained by centrifugation at $2000 \boldsymbol{g}$ for $25 \mathrm{~min}$ at $4{ }^{\circ} \mathrm{C}$ and stored at $-80^{\circ} \mathrm{C}$ until analyses. Calcium, phosphate, and glucose were evaluated by the QuantiChrom assays (BioAssay Systems, Hayward, CA, USA), and alkaline phosphatase (ALP) and total/lipoprotein-associated cholesterol were quantified using the EnzyChrom assays

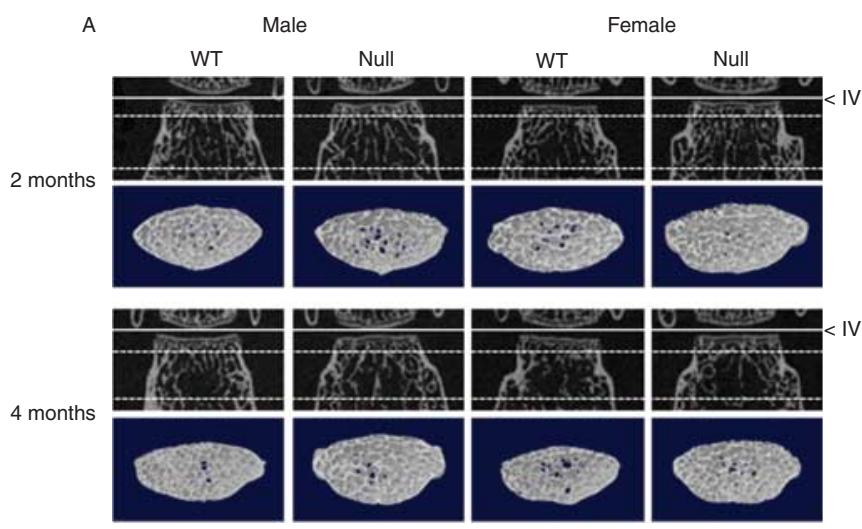

(BioAssay Systems), all according to manufacturer's recommendations. $17 \beta-\mathrm{E}_{2}$ levels were measured with the commercially available ELISA Kits (Cayman Chemical, Ann Arbor, MI, USA) according to the manufacturer's instructions. For determination of plasma levels of corticosterone (Enzo Life Sciences, Farmingdale, NY, USA), ACTH (MyBioSource, San Diego, CA, USA), leptin (Millipore, Billerica, MA, USA), and adiponectin (Millipore), mice were fasted overnight $(16 \mathrm{~h})$; half of them were refed $2 \mathrm{~h}$ before being anaesthetized with Isoflurane (PPC, Richmond Hill, ON, Canada) and whole blood collection. All mice were killed by $\mathrm{CO}_{2}$ asphyxiation following anesthesia and whole blood collection.

\section{Microcomputed X-ray tomography}

After the animals were killed, lumbar vertebrae were harvested and fixed in $4 \%$ paraformaldehyde (PF) in PBS for $16-18 \mathrm{~h}$ at $4{ }^{\circ} \mathrm{C}$. The vertebrae were scanned using a Skyscan 1172c tabletop MicroCT system (Soquelec, Montreal, QC, Canada) with the following parameters: $5 \mu \mathrm{m}$ pixel size, $70 \mathrm{kV} / 100 \mu \mathrm{A}$ tube voltage/current, $1200 \mathrm{~ms}$ exposure time, and a $0.5 \mathrm{~mm}$ aluminium filter. Raw images were optimized and reconstructed using NRecon Software (Skyscan, Aartselar, Belgium); the volumes of interest were defined as 230 slices, 100 slices below the intervertebral space (Fig. 1A). The threshold was set at 80 to discriminate bone from soft tissue and binary images were subsequently analyzed with CTAn (Skyscan) to obtain the following microCT parameters: relative bone

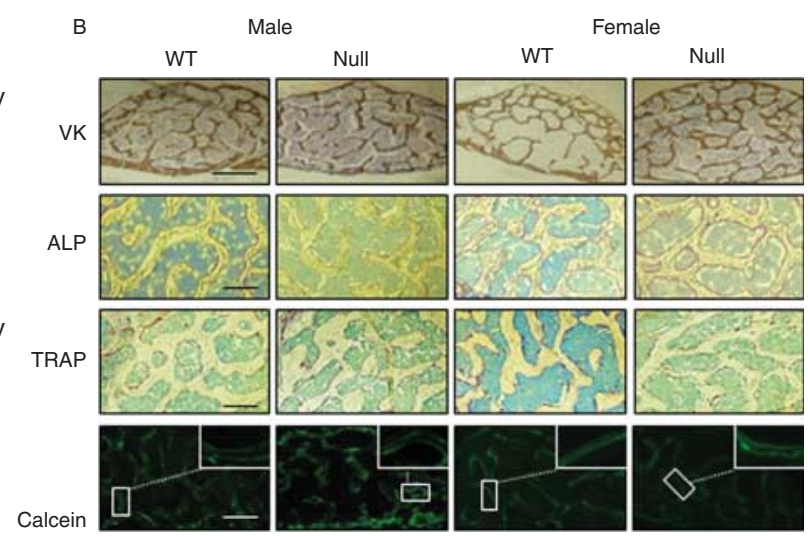

\section{Figure 1}

MicroCT and histological analysis of Scarb1-null mouse vertebrae. (A) Representative 3D renderings of 2- and 4-month-old mouse fourth lumbar vertebrae bone volumes of interest (VOI) and representative 3D renderings of VOI. VOI was defined as a 230 slice thick section of the vertebral body (upper and lower dashed lines) that were selected 100 slices from the intervertebral space (IV, full line), with caudal growth plate facing up. (B) Representative Von Kossa (VK, scale bar $=500 \mu \mathrm{m})$, alkaline phosphatase (ALP, scale bar $=200 \mu \mathrm{m})$, tartrate-resistant acid phosphatase (TRAP, scale bar $=200 \mu \mathrm{m}$ ) stainings, and calcein fronts (top, $10 \times$ digital zoom of typical double-label front and bottom, general labeling, scale bar $=200 \mu \mathrm{m}$ ) from lumbar vertebrae of 2-month-old mice.

Published by Bioscientifica Ltd. 
volume (BV/TV), trabecular thickness (Tb.Th), number of trabeculae (Tb.N), and trabecular spacing (Tb.Sp). Bone mineral density (BMD) was evaluated using a standard curve obtained from hydroxyapatite rods of $2 \mathrm{~mm}$ diameter (Skyscan) scanned with the same parameters.

\section{Static and dynamic histology}

Two-month-old mice were injected twice with $20 \mathrm{mg}$ of calcein (Sigma-Aldrich)/kg body weight 10 and 2 days before being killed. Lumbar vertebrae were dissected and fixed for $16-18 \mathrm{~h}$ in PBS with $4 \% \mathrm{PF}$ at $4{ }^{\circ} \mathrm{C}$. Bones were processed and embedded in low-temperature polymerizing polymethylmethacrylate (Erben 1997), sectioned transaxially starting 20 slices below the caudal growth plate at a $6 \mu \mathrm{m}$ thickness with a rotary HM 360 microtome (Thermo Fisher, Ottawa, ON Canada). Calcein fronts were observed with a fluorescent microscope (Nikon FN1 Eclipse, Mississauga, ON, Canada) and averaged from the top (sections 20-25), middle (sections 35-40), and bottom (sections 45-50) for each sample. In parallel, bone sections were stained with the Von Kossa technique, and for ALP (Millipore) and tartrate-resistant acid phosphatase (TRAP; Dako, Burlington, ON, Canada) activities. Von Kossa, ALP, and TRAP-stained bone sections were visualized under an inverted phase-contrast microscope (TE-300, Nikon) and analyzed with Image (NIH, Bethesda, MD, USA) to evaluate the following static and dynamic parameters: relative osteoblast surface per bone surface (Ob.S/BS on ALP-stained sections), number of osteoclasts (N.Oc/mm on TRAP-stained sections), percent mineralizing surface (MS/BS), mineral apposition rate (MAR), and bone formation rate (BFR/BS). MS/BS was calculated as $\mathrm{dL}+$ $(\mathrm{sL} / 2) / \mathrm{BS}$, where $\mathrm{dL}$ and $\mathrm{SL}$ are double- and single-labeled surfaces respectively.

\section{Marrow-derived stromal cultures}

Femora and tibiae from 2-month-old female WT and null mice were denuded of any soft tissue, sterilized twice for $30 \mathrm{~min}$ in PBS supplemented with $200 \mathrm{U} / \mathrm{ml}$ penicillin-streptomycin (Invitrogen) and 0.2\% FungiZone (Invitrogen) (PBS-PSF), and then transferred into fresh PBS-PSF under a sterile hood. The epiphyses were cut off and marrow was flushed out in to an Eppendorf tube, centrifuged at $5900 \boldsymbol{g}$ for $1 \mathrm{~min}$ in an Eppendorf tabletop centrifuge (Eppendorf, Mississauga, ON, Canada), suspended in PBS, and cell clumps were broken up by repetitive extrusions. The suspension was diluted in $\alpha$ MEM (Invitrogen), containing $25 \mu \mathrm{g} / \mathrm{ml}$ L-ascorbic acid (Sigma-Aldrich).
The marrow cells were plated in $100 \mathrm{~mm}$ dish (Sarstedt, Montréal, QC, Canada; bones from one mouse per dish) and left to adhere for 7 days in aMEM with 10\% FBS (Cansera, Etobicoke, ON, Canada) and $25 \mu \mathrm{g} / \mathrm{ml}$ of L-ascorbic acid (Sigma-Aldrich). Nonadherent cells were then vigorously washed away with PBS-PSF. The cells were left to reach confluence, washed twice with PBS, and then harvested for experimentation.

\section{Osteoblastic differentiation}

Adherent MSCs were harvested and seeded at 50000 cells $/ \mathrm{cm}^{2}$ in 24-well plates (Sarstedt), left to reach confluence, and treated for 21 days in osteogenic medium consisting of MEM (Invitrogen) with $10 \% \mathrm{FBS}, 50 \mu \mathrm{g} / \mathrm{ml}$ L-ascorbic acid, and $3 \mathrm{mM}$ glycerol-2-phosphate (SigmaAldrich). Osteoblastic differentiation was assessed through ALP (Millipore) and Alizarin S (Sigma-Aldrich) staining. Alizarin S was solubilized in 10\% cetylpyridinium chloride and its optical absorbance was read at $575 \mathrm{~nm}$.

\section{Real-time PCR}

The cells were kept for $24 \mathrm{~h}$ in $\alpha \mathrm{MEM}$ with $10 \%$ FBS or in MEM containing 2\% FBS with or without $100 \mathrm{ng} / \mathrm{ml}$ leptin (Sigma-Aldrich) or $10 \mathrm{nM}$ ACTH (Tocris Bioscience, Bristol, UK), lysed with RiboZol (Amresco, Solon, OH, USA), and total RNA was extracted as recommended by the manufacturer. Total RNA was reversed transcribed using AMV RT (Roche) accordingly to the manufacturer's instructions. cDNA was used to carry out PCR with the following primer pairs: reference gene $\beta$-microglobulin (B2m; F, 5'-TACTCACGCCACCCACCGGAG-3' and R, 5'-GCTCGGCCATACTGGCATGCT-3'), osteoblastic markers osterix (Osx/Sp7; F, 5'-TTCGCATCTGAAAGCCCACT-3' and R: $5^{\prime}$-TGCGCTGATGTTTGCTCAAG-3'), collagen type I (Col1a1; F, 5'-ACTTCAGCTTCCTGCCTCAG-3' and R, 5'-GCTTCTTTTCCTTGGGGTTC-3'), and sclerostin (Sost; F, 5'-CAGGAATGATGCCACAGAGGT-3' and R, 5'-GTCTGTCAGGAAGCGGGTG-3'). In parallel, RNA was extracted from white adipose tissue of 2-month-old mice, reverse transcribed, and used to observe the expression of leptin (Lep; F, 5'-TGCGGCCCAGGAGAGGTGAG-3' and R, 5'-AAGCAGCACCCCAGGAGCCT-3'). PCRs were carried out in a MyiQ Thermocycler (Bio-Rad) for 40 cycles, with a denaturation temperature at $95^{\circ} \mathrm{C}(10 \mathrm{~s})$, an annealing temperature at $58^{\circ} \mathrm{C}(30 \mathrm{~s})$, and a $5 \mathrm{~min}$ terminal elongation at $72{ }^{\circ} \mathrm{C}$. Relative fluorescence was analyzed with the iQ5 Software (Bio-Rad).

Published by Bioscientifica Ltd. 
Table 1 Plasmatic parameters in fasted 2-month-old female mice. Values are means \pm S.E.M.; number of mice per group is indicated in parentheses

\begin{tabular}{l} 
Genotype \\
\hline ALP $((\mu \mathrm{mol} \mathrm{p}-\mathrm{NP} /(\mathrm{I} \times \mathrm{min})))$ \\
$\mathrm{Ca}(\mathrm{mg} / \mathrm{dl})$ \\
$\mathrm{Pi}(\mathrm{mg} / \mathrm{dl})$ \\
$\mathrm{Ca} \times \mathrm{Pi}^{\mathrm{a}}\left(\mathrm{mg}^{2} / \mathrm{dl}^{2}\right)$ \\
Glucose $(\mathrm{mg} / \mathrm{dl})$
\end{tabular}

\begin{tabular}{ccc}
\hline WT (5) & & Null (5) \\
\cline { 1 - 1 } $597.6 \pm 47.9$ & & $521.3 \pm 30.3$ \\
$9.0 \pm 0.5$ & & $9.0 \pm 0.8$ \\
$10.0 \pm 0.7$ & & $10.2 \pm 0.6$ \\
$90.2 \pm 11.5$ & & $91.7 \pm 13.6$ \\
$227.9 \pm 27.5$ & & $219.4 \pm 20.7$ \\
\hline
\end{tabular}

${ }^{a}$ The $\mathrm{Ca} \times \mathrm{Pi}$ indices were obtained by multiplying the $\mathrm{Ca}$ and $\mathrm{Pi}$ means within each group, and their relative errors were added to obtain the absolute error of the product.

\section{Statistical analyses}

Data were analysed with the Prism5 Software (GraphPad, La Jolla, CA, USA) for statistical differences. Two-way ANOVAs and multiple comparisons by Bonferroni, as indicated in the figure legend, were applied to determine statistical significance; a $P$ value of 0.05 was considered as the significance threshold. All data are presented as mean \pm s.e.M.

\section{Results}

\section{Higher vertebral bone mass in Scarb1-null female mice}

Previously, we observed a high femoral bone mass phenotype associated with enhanced bone formation in both male and female Scarb1-null mice (Martineau et al. 2014). However, the cortical bone volume of Scarb1-null female mice was increased compared with WT mice, whereas no difference was noted for males (Martineau et al. 2014). Therefore, we further investigated genderspecific bone phenotype and endocrine dysfunction in Scarb1-null mice. Total body weight was not significantly different between WT and Scarb1-null female mice (18.2 \pm 1.1 vs $21.5 \pm 3.8 \mathrm{~g}$ ), and no significant difference was observed in abdominal fat $(0.14 \pm 0.03$ vs $0.19 \pm 0.09 \mathrm{~g})$ and uterus $(0.12 \pm 0.04$ vs $0.14 \pm 0.06 \mathrm{~g})$ weights between 2-month-old WT and Scarb1-null female mice. Similarly, total body weight was not different between male Scarb1null and WT mice (Martineau et al. 2014). To assess whether SR-BI deficiency caused any metabolic, renal, or mineral disorder, plasmatic levels of calcium, phosphate, ALP, and glucose were measured in 2-month-old WT and Scarb1-null females; no significant alterations were detected between WT and Scarb1-null female mice (Table 1), being similar to male mice (Martineau et al. 2014).

Representative microtomographic renderings from lumbar vertebrae qualitatively showed alterations in bone architecture (Fig. 1A). Two-month-old Scarb1-null female mice showed higher relative bone volume, increased Tb.N, and BMD, as well as lower Tb.Sp compared with female WT mice (Table 2). The relative vertebral bone mass of Scarb1-null female mice thereafter was similar to control values at 4 months of age. Tb.Th values remained unaffected at 2 months, yet they were significantly lower at 4 months. In contrast, microtomographic analysis revealed unchanged vertebral structure in 2-month-old Scarb1-null male mice (Table 2), but Tb.Th was also reduced in 4-month-old Scarb1-null male mice.

\section{Enhanced bone formation in the vertebrae from Scarb1-null female mice}

To assess whether this higher lumbar bone mass was due to either altered osteoblastic or osteoclastic functions, histochemistry was performed on samples from 2-monthold mice (Fig. 1B for representative bone sections).

Table 2 MicroCT analysis parameter values in 2- and 4-month-old WT and null mice lumbar vertebrae. Values are mean \pm S.E.M.; number of mice per group is indicated in parentheses

\begin{tabular}{|c|c|c|c|c|c|c|c|c|}
\hline & \multicolumn{4}{|c|}{ Female } & \multicolumn{4}{|c|}{ Male } \\
\hline & \multicolumn{2}{|c|}{2 months } & \multicolumn{2}{|c|}{4 months } & \multicolumn{2}{|c|}{2 months } & \multicolumn{2}{|c|}{4 months } \\
\hline & WT (13) & Null (13) & WT (12) & Null (12) & WT (12) & Null (10) & WT (12) & Null (12) \\
\hline BV/TV (\%) & $32.7 \pm 0.4$ & $37.9 \pm 0.7^{\ddagger}$ & $37.8 \pm 1.6$ & $37.3 \pm 1.0$ & $35.9 \pm 1.2$ & $34.5 \pm 1.0$ & $35.0 \pm 0.6$ & $32.3 \pm 0.8$ \\
\hline Tb.N (/mm) & $6.2 \pm 0.1$ & $7.0 \pm 0.1^{\dagger}$ & $6.3 \pm 0.2$ & $6.5 \pm 0.1$ & $6.6 \pm 0.1$ & $6.9 \pm 0.3$ & $6.0 \pm 0.1$ & $6.4 \pm 0.1$ \\
\hline Tb.Sp ( $\mu \mathrm{m})$ & $150.5 \pm 2.3$ & $136.9 \pm 2.2 *$ & $157.0 \pm 5.4$ & $164.7 \pm 4.1$ & $130.7 \pm 3.1$ & $136.2 \pm 5.9$ & $146.4 \pm 2.8$ & $136.7 \pm 3.0$ \\
\hline Tb.Th $(\mu \mathrm{m})$ & $55.2 \pm 1.9$ & $52.3 \pm 1.9$ & $65.1 \pm 1.7$ & $56.4 \pm 1.1^{\dagger}$ & $54.5 \pm 2.3$ & $50.6 \pm 1.9$ & $57.0 \pm 1.4$ & $49.7 \pm 0.8 *$ \\
\hline BMD $\left(\mathrm{g} / \mathrm{cm}^{3}\right)$ & $0.21 \pm 0.01$ & $0.28 \pm 0.02 *$ & $0.32 \pm 0.02$ & $0.23 \pm 0.01$ & $0.25 \pm 0.02$ & $0.26 \pm 0.02$ & $0.23 \pm 0.06$ & $0.21 \pm 0.01$ \\
\hline
\end{tabular}

Significant differences vs WT of corresponding age group: ${ }^{*} P<0.05,{ }^{\dagger} P<0.01$ and ${ }^{\ddagger} P<0.001$, Bonferroni's post hoc test. BV/TV, relative bone volume; Tb.N, number of trabeculae; Tb.Sp, trabecular spacing; Tb.Th, trabecular thickness; BMD, bone mineral density.

http://joe.endocrinology-journals.org DOI: $10.1530 / J O E-14-0147$
(C) 2014 Society for Endocrinology Printed in Great Britain
Published by Bioscientifica Ltd. 
Table 3 Static and dynamic analyses parameter values in 2-month-old WT and null female and male mice vertebrae. Values are mean \pm s.E.M.; number of mice per group is indicated in parentheses

\begin{tabular}{|c|c|c|c|c|}
\hline & \multicolumn{2}{|c|}{ Female } & \multicolumn{2}{|c|}{ Male } \\
\hline & WT (8) & Null (7) & WT (6) & Null (7) \\
\hline Single-labeled surface (\%) & $27.0 \pm 2.3$ & $36.8 \pm 3.2^{*}$ & $30.1 \pm 3.4$ & $35.9 \pm 2.4$ \\
\hline Double-labeled surface (\%) & $15.0 \pm 1.9$ & $21.4 \pm 1.0$ & $11.5 \pm 0.9$ & $10.9 \pm 1.1$ \\
\hline Trabecular MAR ( $\mu \mathrm{m} /$ day) & $2.79 \pm 0.21$ & $3.62 \pm 0.21$ * & $2.71 \pm 0.27$ & $3.02 \pm 0.19$ \\
\hline MS/BS (\%) & $27.5 \pm 2.8$ & $33.1 \pm 2.2^{\dagger}$ & $23.9 \pm 1.7$ & $25.1 \pm 1.4$ \\
\hline Ob.S/BS (\%) & $22.3 \pm 1.8$ & $33.4 \pm 3.1^{\dagger}$ & $30.5 \pm 2.2$ & $27.5 \pm 1.6$ \\
\hline $\mathrm{N} . \mathrm{Oc} / \mathrm{mm}$ & $3.5 \pm 0.2$ & $3.9 \pm 0.8$ & $4.2 \pm 0.3$ & $4.6 \pm 0.7$ \\
\hline BFR/BS $\left(\mu \mathrm{m}^{2} / \mu \mathrm{m}\right.$ per day) & $0.83 \pm 0.12$ & $1.15 \pm 0.11 *$ & $0.63 \pm 0.06$ & $0.75 \pm 0.07$ \\
\hline
\end{tabular}

Significant differences vs WT: ${ }^{*} P<0.05$ and ${ }^{\dagger} P<0.01$, Bonferroni's post hoc test. MAR, mineral apposition rate; MS/BS, mineralizing surface; Ob.S/BS, relative osteoblast surface per bone surface; N.Oc/mm, number of osteoclasts; BFR/BS, bone formation rate.

Von Kossa staining showed more mineralized tissue in the vertebrae from Scarb1-null female mice. Concomitantly, the ALP staining was visibly enhanced in the vertebrae from Scarb1-null female mice, whereas ALP staining of bone sections from male WT and Scarb1-null mice was similar. The TRAP staining remained similar between WT mice and Scarb1-null mice of both genders, indicating a predominantly osteoblastic alteration. In accordance, the relative Ob.S/BS was significantly higher in the vertebra from Scarb1-null female mice, as the N.Oc/mm remained unaffected (Table 3). Dynamic histological evaluation yielded similar results, as lumbar MARs and BFRs were enhanced in the Scarb1-null female mice (Fig. 1B for typical calcein fronts).

\section{Disrupted GC/ACTH and leptin/adiponectin axes in null females}

As SR-BI is involved in lipoprotein metabolism (van der Velde \& Groen 2005), we measured the cholesterol plasma profile in Scarb1-null mice. The fractions of total plasma cholesterol and HDL-C were increased at similar levels in Scarb1-null males and females (Fig. 2), which suggests that gender-specific differences in vertebral bone mass in Scarb1-null mice is not related to differences in HDL level.

As we and others have previously reported an impaired corticosterone response to fasting and constitutive high plasma levels of ACTH in male Scarb1-null mice (Hoekstra et al. 2008, Martineau et al. 2014), we asked whether differences in the GC/ACTH axis may also be exhibited by female Scarb1-null mice. The Scarb1null females showed impaired corticosteroid response following fasting (Fig. 3A); this condition was accompanied by higher levels of ACTH under refed condition in
Scarb1-null females (Fig. 3B). This relationship is better illustrated in Fig. 3C, as the GC/ACTH ratio is reduced in the refed condition for Scarb1-null females. Though being significantly lower in all null mice vs WT mice, the GC and ACTH variation between fasting and refed states tended to be greater in female Scarb1-null mice when compared to the null males, however, without reaching statistical significance (Fig. 3D). Our results suggest that genderspecific differences in vertebral bone mass in Scarb1-null mice are not related to GC/ACTH axis. As vertebral high bone mass was specific to female Scarb1-null mice, we measured plasma estrogen levels. No difference for total $\mathrm{E}_{2}$ plasma levels between WT and Scarb1-null female mice was detected (Fig. 4).

As $\mathrm{E}_{2}$ status was unaffected in our model and given that several studies have observed region- and

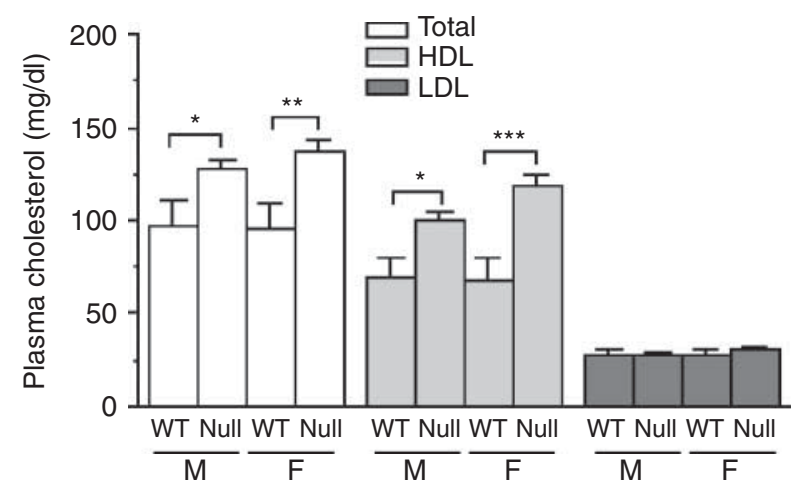

Figure 2

Plasma cholesterol levels in fasted 2-month-old male and female WT and Scarb1-null mice. Total, HDL- and LDL-associated cholesterol fractions from plasma were quantified the BioAssay systems Enzychrom Kit. Values are mean \pm S.E.M. from four mice in each group. Significant differences $\left({ }^{*} P<0.05, * * P<0.01\right.$, and $\left.* * * P<0.001\right)$ for WT vs null mice, a two-way ANOVA followed by Bonferroni's post hoc test. 

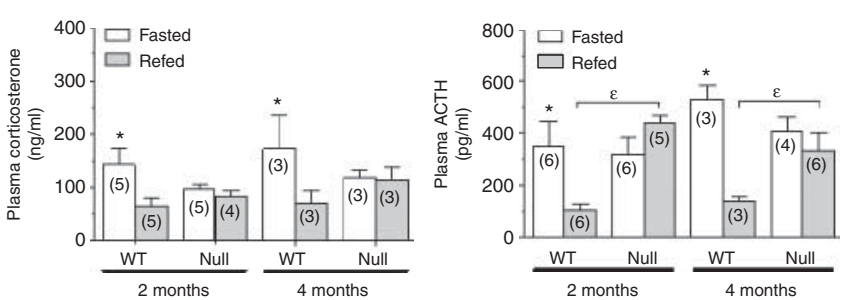

c

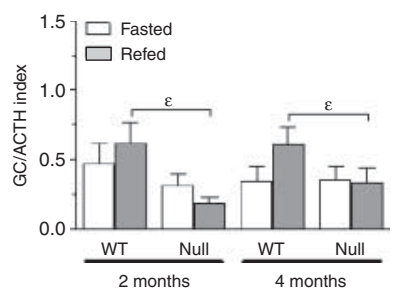

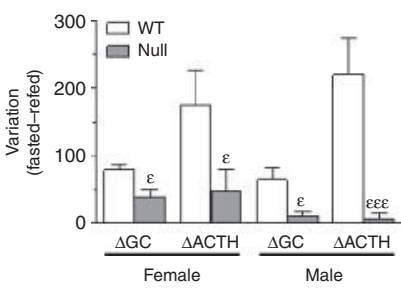

Figure 3

Serological analysis of the glucocorticoid (GC)/ACTH axis in 2- and 4-monthold WT and Scarb1-null female mice. (A) Corticosterone and (B) ACTH levels were measured by ELISA in fasting ( $16 \mathrm{~h}$ ) and refed $(2 \mathrm{~h})$ female mice. Values are mean \pm S.E.M. and number of mice is indicated in parentheses. Significant difference $\left({ }^{*} P<0.05\right)$ for fasted vs refed state and ${ }^{\varepsilon} P<0.05$ for WT vs null mice in refed condition, two-way ANOVA followed by

Bonferroni's post hoc test. (C) GC/ACTH ratio obtained from the averages of

gender-specific effect of leptin (Thomas et al. 2001, Hamrick et al. 2004, Wang et al. 2007), we questioned whether leptinemia was affected in null mice. As expected, plasma levels of leptin were increased by feeding in both WT genders as well as null males (Fig. 5A and B). However, plasma levels of leptin were constantly elevated in fasted Scarb1-null female mice compared with the corresponding WT mice, which translates in reduced leptin induction in refed mice (Fig. 5C). This was not observed in males. No difference between WT and Scarb1-null mice was noticed for adiponectin (fasting values in 2-month-old females: $1.9 \pm 0.1 \mathrm{ng} / \mathrm{ml}$ in WT vs $2.0 \pm 0.2 \mathrm{ng} / \mathrm{ml}$ in null mice, four per group). As the white adipose tissue is the main source of leptin production (Guerre-Millo 2004), we verified its expression in WT and null mice. We measured a 2.5-fold increase in Lep gene expression in white adipose tissue from the female null mice compared with their WT counterparts (Fig. 5D). Such difference was not observed in male mice.

\section{In vitro osteoblasts' response to leptin and ACTH}

We recently reported that MSCs from Scarb1-null male mice have enhanced proliferation rate and differentiation potential (Martineau et al. 2014). Similarly, enhanced rates of proliferation (1.5-fold) and higher ALP activity with increased matrix mineralization (1.8-fold) were observed in null MSCs from female mice (data not shown). In addition, gene expression of the osteoblastic transcription factor $O s x / S p 7$ was also upregulated in null MSCs from females (Fig. 6A), whereas Col1a1 was not different (Fig. 6B) and Sost was downregulated (Fig. 6C); similar observations were made in cells isolated from male mice (Osx/Sp7, 2.3-fold; Sost, 0.4-fold vs WT, data not shown). datasets $A$ and $B$. Significant differences $\left({ }^{8} P<0.05\right)$ for WT vs null mice in refed condition, two-way ANOVA followed by Bonferroni's post hoc test. (D) Differences between female and male mice for plasma levels of corticosterone $(\triangle \mathrm{GC})$ and $\mathrm{ACTH}(\triangle \mathrm{ACTH})$ obtained from the averages of datasets $A$ and $B$ for females, and data from the Martineau et al. (2014) study for males. Significant differences $\left({ }^{\varepsilon} P<0.05\right.$ and $\left.{ }^{\varepsilon \varepsilon \varepsilon} P<0.001\right)$ for WT vs null mice, two-way ANOVA followed by Bonferroni's post hoc test.

Following treatment with leptin or ACTH, gene expression of Col1a1 was increased in MSCs from WT and Scarb1-null female mice (Fig. 6B). In contrast, gene expression of $O s x / S p 7$ and Sost was not further regulated by ACTH and leptin in MSCs from Scarb1-null female mice (Fig. 6A and C).

\section{Discussion}

Recently, we have reported enhanced trabecular bone formation in the femora from Scarb1-null mice (Martineau et al. 2014). Interestingly, differences between males and females were observed in cortical bone volume of Scarb1null mice, which was increased compared with WT mice in females only (Martineau et al. 2014). This current study further assessed gender-specific bone alterations in Scarb1null mice. Our data indicate that 2-month-old Scarb1-null

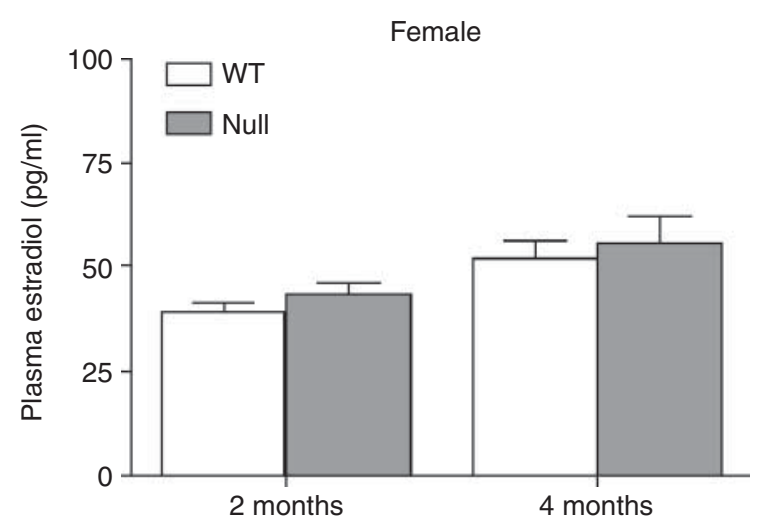

Figure 4

Estradiol $\left(E_{2}\right)$ plasma levels in WT and Scarb1-null mice. Total $E_{2}$ levels were measured by ELISA in fasted 2- and 4-month-old female mice. Values are mean \pm S.E.M. from five mice per group.

Published by Bioscientifica Ltd. 


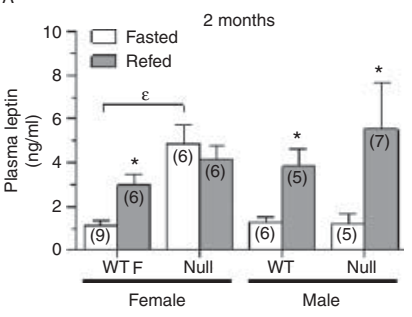

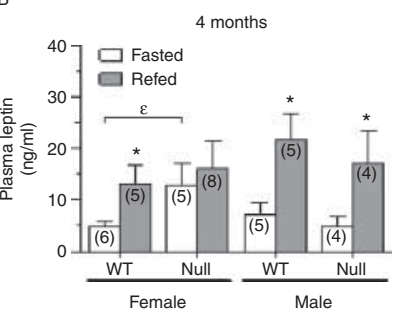

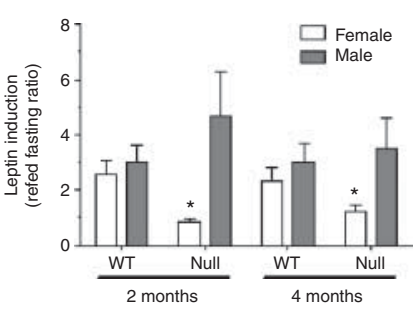

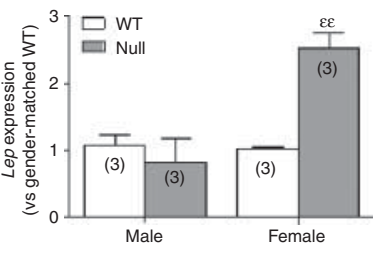

Figure 5

Plasma levels of leptin and gene expression of Lep in adipose tissue from WT and Scarb1-null mice. (A and B) Plasma levels of leptin were measured by ELISA in fasting and refed WT and Scarb1-null mice. Values are mean \pm S.E.M. and number of mice is indicated in parentheses. Significant differences when compared to fasted state $(* P<0.05)$ or compared with WT mice $\left({ }^{\varepsilon} P<0.05\right)$, two-way ANOVA followed by Bonferroni's post hoc test. (C) Leptin induction in refed mice from the females have higher vertebral bone mass concurrent with greater BFR, whereas no difference was seen in male Scarb1-null mice compared with WT mice. Therefore, we explored the potential conditions responsible for this gender difference. Higher levels of total cholesterol and HDL-C were measured in both male and female Scarb1null mice, in accordance with the role of SR-BI in HDL metabolism. Impaired corticosterone response to fasting and constitutive high plasma ACTH levels were measured in female null mice, as in males (Martineau et al. 2014). ACTH promoted in vitro osteoblast differentiation of WT MSCs as evidenced by increased gene expression of Osx/Sp7 and Col1a1 and reduced Sost gene expression, indicating that ACTH may contribute to the high bone mass phenotype of null mice. In contrast, high plasma leptin levels and enhanced Lep gene expression in adipose tissue were seen in null females only. Moreover, leptin had anabolic effects in vitro by increasing differentiation of WT MSCs through upregulation of $O s x / S p 7$ and Col1a1 expression and reduced Sost expression, suggesting that increased plasma leptin may account for the genderspecific high bone mass seen in the femoral cortical region and vertebrae of null females. In addition to these anabolic systemic conditions, MSCs from Scarb1-null females displayed enhanced proliferation (data not shown) and differentiation potentials, as observed in null MSCs from male mice (Martineau et al. 2014).

High bone mass phenotype in Scarb1-null mice seemingly contradicts a positive correlation between efficient HDL metabolism and bone mass, suggested by several studies (Ackert-Bicknell 2012). In accordance with its role in reverse cholesterol transport (RCT), Scarb1-null mice were shown to be prone to atherosclerosis (Huby et al. 2006) due to impaired selective uptake of cholesteryl esters averages of datasets A and B. Significant differences $(* P<0.05)$ for WT vs null mice, two-way ANOVA followed by Bonferroni's post hoc test (D) Gene expression of Lep in adipose tissue from 2-month-old WT and Scarb1-null mice. Values are mean \pm S.E.M. and number of mice is indicated in parentheses. Significant difference $\left({ }^{\varepsilon \varepsilon} P<0.01\right)$ vs WT mice, two-way ANOVA followed by Bonferroni's post hoc test.

from HDL by the liver and associated with abnormally cholesterol-enriched HDL particles (Rigotti et al. 1997). Therefore, the contribution of SR-BI to efficient RCT appears to be unrelated to the bone alterations in Scarb1null mice. Moreover, a positive correlation between levels of HDL-C and bone mass has also been reported in experimental mouse strains (Mouse Phenome Database, Jackson Laboratories), underscoring its significance for bone metabolism. In accordance, both male and female Scarb1-null mice show similar high levels of total cholesterol and HDL-C that could account for the higher bone mass phenotype of these mice, but not for gender differences in bone status. Our results show that 2-monthold Scarb1-null female mice have higher bone mass and enhanced formation rate in lumbar vertebrae, whereas no significant alteration was observed in males. Such genderassociated bone features were also noted in femoral cancellous and cortical bone from Scarb1-null female mice (Martineau et al. 2014). These data indicate that SR-BI deficiency is associated with gender-specific differences in skeletal phenotype. Overall, the absence of SR-BI translates in a more generalized high bone mass phenotype in female mice, whereas this was limited to trabecular bone in Scarb1null males (Martineau et al. 2014).

Considering the high expression of SR-BI in ovaries and adrenal glands (Rigotti et al. 1997), relevant hormonal axes were explored. Impaired corticosterone response to fasting accompanied by constant high ACTH levels was observed in Scarb1-null females, similarly to Scarb1-null males (Hoekstra et al. 2008, Martineau et al. 2014). As ACTH is recognized to have anabolic effects on bone metabolism (Isales et al. 2010), its higher plasma levels correlate with the high bone mass of both male and female Scarb1-null mice. Therefore, such systemic alterations in

Published by Bioscientifica Ltd. 

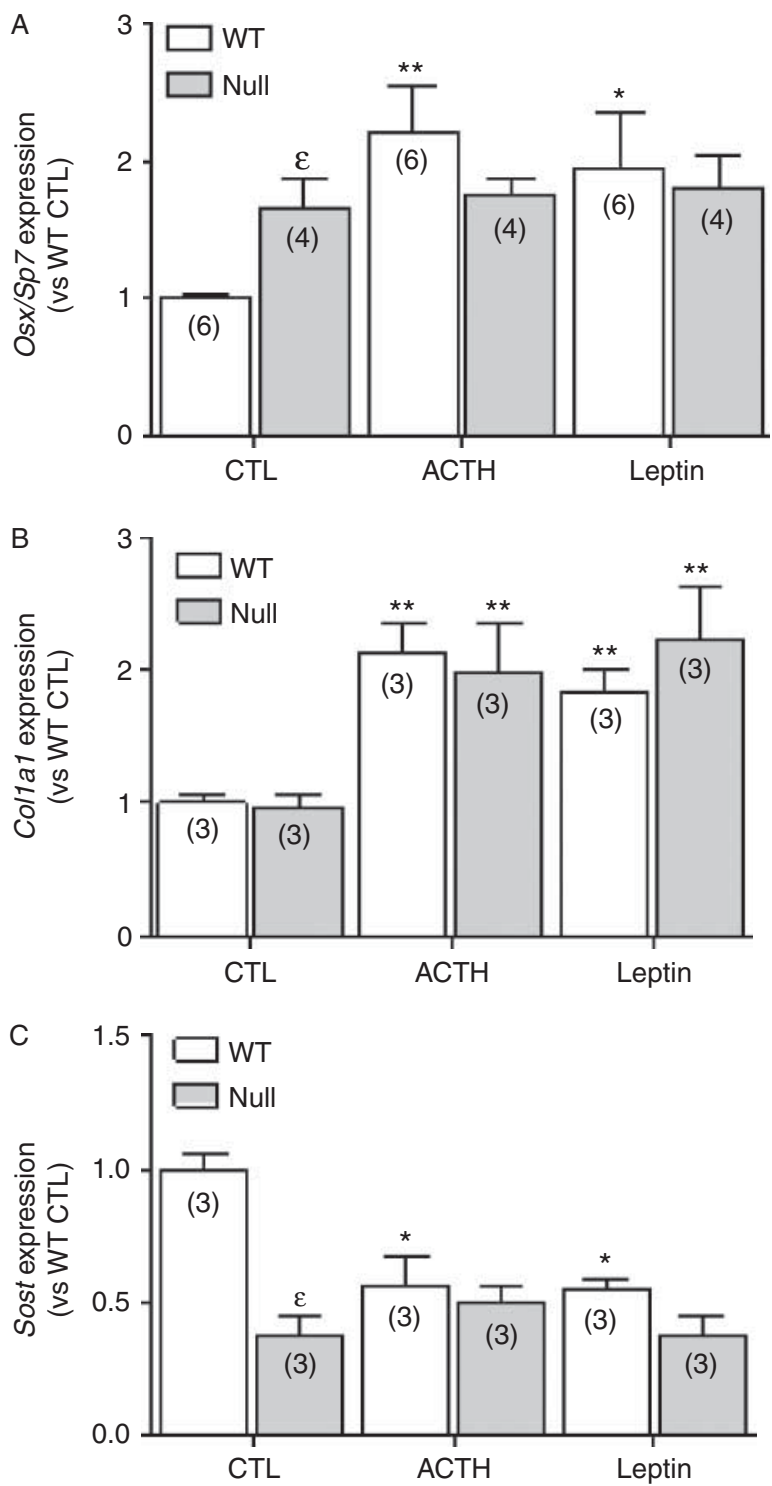

\section{Figure 6}

Response of MSCs from WT and Scarb1-null mice to ACTH and leptin. Realtime gene expression analysis of osteoblastic markers $\mathrm{Osx} / \mathrm{Sp} 7$ (A), Col1a1 (B), and Sost (C) without (CTL) or with addition of $10 \mathrm{nM} \mathrm{ACTH} \mathrm{or} 100 \mathrm{ng} / \mathrm{ml}$ leptin to the culture medium for $24 \mathrm{~h}$. Values are mean \pm s.E.M. and number of cell preparations is indicated in parentheses. Significant differences when compared with CTL condition ( $* P<0.05$ and $* * P<0.01)$ or compared with WT mice $\left({ }^{\circledR} P<0.05\right)$, two-way ANOVA followed by Bonferroni's post hoc test.

both genders of Scarb1-null mice constitute anabolic conditions for bone formation, agreeing with the observed high bone mass phenotype. Nevertheless, gender differences in bone phenotypes of Scarb1-null mice may not rely on the GC/ACTH axis alterations. We next investigated whether $\mathrm{E}_{2}$, a powerful bone growth modulator (Frenkel et al. 2010), was affected in Scarb1-null females. Total $\mathrm{E}_{2}$ levels were normal in Scarb1-null females, therefore discarding the disruption of this hormonal axis as a major factor for the gender-specific bone alterations. Though female Scarb1-null females show reduced fertility (Miettinen et al. 2001), their ovarian functions are normal in terms of progesterone and $\mathrm{E}_{2}$ production (Rigotti et al. 2003), indicating existing compensatory mechanisms in some aspects. Moreover, HDL carries a large proportion of esterified estrogens in the bloodstream (Hockerstedt et al. 2002); it is unknown whether Scarb1 deficiency impacts the distribution of $\mathrm{E}_{2}$ esters vs free $\mathrm{E}_{2}$.

As SR-BI was shown to be abundantly expressed in fat tissue (Acton et al. 1994), plasma levels of leptin and adiponectine were measured in null mice. Leptin is recognized as an important bone growth modulator (Fleet 2000, Turner et al. 2013). Null females showed high plasma levels of leptin under fasting conditions, as leptinemia was normal in Scarb1-null males, suggesting that leptin may explain the gender differences observed in bone status. Leptin is primarily produced by white adipose tissue and its plasma levels generally correlate with body fat. Though no difference in abdominal fat weight was noticed between WT and Scarb1-null females, greater Lep expression was observed in white adipose tissue from null females, implying alterations of adipocyte function. To note, the majority of adipocyte cholesterol originates from circulating lipoproteins (Yu et al. 2010). As SR-BI is abundantly expressed in fat tissue and promotes cholesterol uptake from HDL (Tondu et al. 2005), cholesterol balance in Scarb1-null adipocytes might be deregulated. Such cholesterol imbalance is the characteristic of hypertrophied adipocytes that translates to alterations in their metabolism and gene expression (Le Lay et al. 2001, Jernas et al. 2006, Yu et al. 2010).

Leptin has been demonstrated to promote HDL clearance (Lundasen et al. 2003) and defective HDL metabolism was reported in leptin-deficient $(o b / o b)$ and leptin receptor-deficient $(d b / d b)$ mice (Silver et al. 1999, 2000), evoking that a potential cross talk between these two axes may occur. In accordance, leptin induces SR-BI expression in the liver of $o b / o b$ mice (Lundasen et al. 2003). Of interest, estrogen increases SR-BI expression in adrenals and ovaries (Lopez \& McLean 2006). Furthermore, estrogen influences adipogenesis and adipose metabolism (reviewed in Mattsson \& Olsson (2007)). Though no difference was observed in $\mathrm{E}_{2}$ levels between WT and null females, the higher levels naturally occurring in females could induce disorders absent in males. Also, the transient nature of the higher bone mass observed in Scarb1-null females despite sustained high leptinemia may underlie an acquired leptin resistance phenomenon,

Published by Bioscientifica Ltd. 
perhaps through the modulation of leptin receptors as observed in models of age-related or diet-induced obesity (Martin et al. 2008). Furthermore, this phenotype may be stage specific, as males tend to achieve peak bone mass later than females (Rizzoli et al. 2001, Bonjour et al. 2009, Stagi et al. 2013); we cannot discard this augmented bone mass as it might occur at another time point. Further studies are warranted to determine how the absence of SRBI alters the functions of adipocytes in female mice only and whether injection of leptin to male Scarb1-null mice mimics the bone phenotype of female Scarb1-null mice.

Although the altered endocrine condition in the female Scarb1-null mice likely exerts a significant influence on bone metabolism, we explored potential cellular defects in MSCs. Our results indicate that Scarb1-null MSCs from females displayed a greater proliferation rate, similar to null MSCs from males (Martineau et al. 2014); enhanced proliferation was also reported in SR-BI-deficient lymphocytes (Feng et al. 2011). Our data also indicate enhanced ALP activity and matrix mineralization, as well as enhanced gene expression of $O s x / S p 7$ in MSCs from Scarb1-null females, similarly to male mice (Martineau et al. 2014). Therefore, intrinsic alterations of MSCs correlate with the high bone mass phenotype of Scarb1-null mice. Moreover, we measured reduced gene expression of Sost in null MSCs from females, as observed in males. The Sost gene product, sclerostin, is a factor known to inhibit osteoblastic differentiation (Komori 2013), and its down regulation in the absence of SR-BI also correlates with the bone phenotype of Scarb1-null mice.

Several studies argue that leptin decreases bone accrual through a hypothalamic relay (Fleet 2000). In contrast, other studies rather suggest that leptin acts directly on osteoblasts and increases cell proliferation and differentiation; it has been proposed that peripheral leptin has anabolic bone effects, whereas its hypothalamic actions are catabolic (Motyl \& Rosen 2012). To determine whether Scarb1 deficiency affected MSC response to this hormone, we verified the expression of Col1a1 and $O s x / S p 7$, two factors known to be induced by leptin exposure in osteoblasts (Gordeladze et al. 2002, Zhou et al. 2012). Both WT and null MSCs showed increased Col1a1 gene expression in response to leptin, indicating that it promotes their osteoblastic differentiation. However, the induction of $O s x / S p 7$ expression by leptin treatment was significant in the WT cells only due to its basal overexpression in null cells. Also, leptin treatment shows no effect on Sost gene expression in null MSCs due to its reduced basal expression. Thus, Scarb1 deficiency does not overtly alter the response of MSCs to ACTH or leptin, but rather influences basal genetic expression in these cells, seemingly rendering them less sensitive to these hormones effects.

There is evidence in humans for gender-specific association of leptin with bone metabolism. Plasma leptin levels correlate positively with bone mass in women, as the opposite is noted in men (Weiss et al. 2006). Epidemiological studies also state a positive correlation between blood leptin levels and bone quality in nonobese premenopausal women (Cirmanova et al. 2008). Furthermore, gender differences in leptin function in bone development have also been suggested with higher leptin receptor expression in female vs male rats (Li et al. 2011). Moreover, subcutaneous leptin replacement in $o b / o b$ mice resulted in increased trabecular bone area mainly in lumbar vertebra and to a lower extent in femur (Turner et al. 2013), which agrees with the bone phenotype of female Scarb1-null mice in which hyperleptinemia is associated with enhanced bone formation in vertebrae and cortical bone; however, work remains to be done to understand why leptinemia is affected in females only.

\section{Conclusions}

We have associated SR-BI deficiency to higher vertebral and femoral bone mass in female mice, seemingly related to both systemic and cell-autonomous mechanisms. First, constitutively high plasma ACTH and leptin levels arguably account for an important part of the augmented bone mass. Second, adipose tissue metabolism seems to be altered in females only, leading to gender-specific leptin increases. Finally, MSCs from Scarb1-null female mice show enhanced osteoblast functions, which may also contribute to augmented bone mass.

\section{Declaration of interest}

The authors declare that there is no conflict of interest that could be perceived as prejudicing the impartiality of the research reported.

\section{Funding}

This work was supported by grants from the Canadian Institute of Health Research (R M, CIHR MOP-89958). C M is recipient of scholarships from the Natural Sciences and Engineering Research Council (NSERC) of Canada.

\section{Author contribution statement}

The authors have made the following declarations about their contributions: study design: L B and R M. Study conduct: C M and L M-F. Data collection: $C M$ and $L M-F$. Data analysis: $C M$ and $R M$. Data interpretation: $C M$ and $R$ M. Drafting manuscript: $C M$ and $R M$. Revising manuscript

Published by Bioscientifica Ltd 
content: $C M, L B$ and $R M$. Approving final version of manuscript: $C M, L M-F, L B$, and $R M . R M$ takes responsibility for the integrity of the data analysis.

\section{References}

Ackert-Bicknell CL 2012 HDL cholesterol and bone mineral density: is there a genetic link? Bone 50 525-533. (doi:10.1016/j.bone.2011. 07.002)

Acton SL, Scherer PE, Lodish HF \& Krieger M 1994 Expression cloning of SR-BI, a CD36-related class B scavenger receptor. Journal of Biological Chemistry 269 21003-21009.

Acton S, Rigotti A, Landschulz KT, Xu S, Hobbs HH \& Krieger M 1996 Identification of scavenger receptor SR-BI as a high density lipoprotein receptor. Science 271 518-520. (doi:10.1126/science.271. 5248.518)

Adami S, Braga V, Zamboni M, Gatti D, Rossini M, Bakri J \& Battaglia E 2004 Relationship between lipids and bone mass in 2 cohorts of healthy women and men. Calcified Tissue International 74 136-142. (doi:10.1007/s00223-003-0050-4)

Banks LM, Lees B, MacSweeney JE \& Stevenson JC 1994 Effect of degenerative spinal and aortic calcification on bone density measurements in post-menopausal women: links between osteoporosis and cardiovascular disease? European Journal of Clinical Investigation $\mathbf{2 4}$ 813-817. (doi:10.1111/j.1365-2362.1994.tb02024.x)

Barengolts EI, Berman M, Kukreja SC, Kouznetsova T, Lin C \& Chomka EV 1998 Osteoporosis and coronary atherosclerosis in asymptomatic postmenopausal women. Calcified Tissue International 62 209-213. (doi:10.1007/s002239900419)

Bonjour JP, Chevalley T, Ferrari S \& Rizzoli R 2009 The importance and relevance of peak bone mass in the prevalence of osteoporosis. Salud Pública de México 51(Suppl 1) S5-S17.

Brodeur MR, Luangrath V, Bourret G, Falstrault L \& Brissette L 2005 Physiological importance of SR-BI in the in vivo metabolism of human HDL and LDL in male and female mice. Journal of Lipid Research 46 687-696. (doi:10.1194/jlr.M400165-JLR200)

Brodeur MR, Brissette L, Falstrault L, Luangrath V \& Moreau R 2008 Scavenger receptor of class B expressed by osteoblastic cells are implicated in the uptake of cholesteryl ester and estradiol from LDL and HDL3. Journal of Bone and Mineral Research 23 326-337. (doi:10.1359/jbmr.071022)

Callewaert F, Sinnesael M, Gielen E, Boonen S \& Vanderschueren D 2010 Skeletal sexual dimorphism: relative contribution of sex steroids, GH-IGF1, and mechanical loading. Journal of Endocrinology 207 127-134. (doi:10.1677/JOE-10-0209)

Cirmanova V, Bayer M, Starka L \& Zajickova K 2008 The effect of leptin on bone: an evolving concept of action. Physiological Research 57(Suppl 1) S143-S151.

Clarke B 2008 Normal bone anatomy and physiology. Clinical Journal of the American Society of Nephrology 3(Suppl 3) S131-S139. (doi:10.2215/CJN. 04151206)

Cuchel M \& Rader DJ 2006 Macrophage reverse cholesterol transport: key to the regression of atherosclerosis? Circulation 113 2548-2555. (doi:10.1161/CIRCULATIONAHA.104.475715)

Erben RG 1997 Embedding of bone samples in methylmethacrylate: an improved method suitable for bone histomorphometry, histochemistry, and immunohistochemistry. Journal of Histochemistry and Cytochemistry 45 307-313. (doi:10.1177/002215549704500215)

Feng H, Guo L, Wang D, Gao H, Hou G, Zheng Z, Ai J, Foreman O, Daugherty A \& Li XA 2011 Deficiency of scavenger receptor BI leads to impaired lymphocyte homeostasis and autoimmune disorders in mice. Arteriosclerosis, Thrombosis, and Vascular Biology 31 2543-2551. (doi:10.1161/ATVBAHA.111.234716)
Fleet JC 2000 Leptin and bone: does the brain control bone biology? Nutrition Reviews 58 209-211. (doi:10.1111/j.1753-4887.2000. tb01864.x)

Frenkel B, Hong A, Baniwal SK, Coetzee GA, Ohlsson C, Khalid O \& Gabet Y 2010 Regulation of adult bone turnover by sex steroids. Journal of Cellular Physiology 224 305-310. (doi:10.1002/jcp.22159)

Gordeladze JO, Drevon CA, Syversen U \& Reseland JE 2002 Leptin stimulates human osteoblastic cell proliferation, de novo collagen synthesis, and mineralization: impact on differentiation markers, apoptosis, and osteoclastic signaling. Journal of Cellular Biochemistry $\mathbf{8 5}$ 825-836. (doi:10.1002/jcb.10156)

Guerre-Millo M 2004 Adipose tissue and adipokines: for better or worse. Diabetes \& Metabolism 30 13-19. (doi:10.1016/S1262-3636(07)70084-8)

Hamrick MW, Pennington C, Newton D, Xie D \& Isales C 2004 Leptin deficiency produces contrasting phenotypes in bones of the limb and spine. Bone 34 376-383. (doi:10.1016/j.bone.2003.11.020)

Hegsted DM 2001 Fractures, calcium, and the modern diet. American Journal of Clinical Nutrition 74 571-573.

Hockerstedt A, Tikkanen MJ \& Jauhiainen M 2002 LCAT facilitates transacylation of $17 \beta$-estradiol in the presence of HDL3 subfraction. Journal of Lipid Research 43 392-397.

Hoekstra M, Meurs I, Koenders M, Out R, Hildebrand RB, Kruijt JK, van Eck M \& Van Berkel TJ 2008 Absence of HDL cholesteryl ester uptake in mice via SR-BI impairs an adequate adrenal glucocorticoidmediated stress response to fasting. Journal of Lipid Research 49 738-745. (doi:10.1194/jlr.M700475-JLR200)

Hoekstra M, van der Sluis RJ, van Eck M \& Van Berkel TJ 2013 Adrenalspecific scavenger receptor BI deficiency induces glucocorticoid insufficiency and lowers plasma very-low-density and low-density lipoprotein levels in mice. Arteriosclerosis, Thrombosis, and Vascular Biology 33 e39-e46. (doi:10.1161/ATVBAHA.112.300784)

Huby T, Doucet C, Dachet C, Ouzilleau B, Ueda Y, Afzal V, Rubin E, Chapman MJ \& Lesnik P 2006 Knockdown expression and hepatic deficiency reveal an atheroprotective role for SR-BI in liver and peripheral tissues. Journal of Clinical Investigation 116 2767-2776. (doi:10.1172/JCI26893)

Hughes FJ, Turner W, Belibasakis G \& Martuscelli G 2006 Effects of growth factors and cytokines on osteoblast differentiation. Periodontology $\mathbf{4 1}$ 48-72. (doi:10.1111/j.1600-0757.2006.00161.x)

Isales CM, Zaidi M \& Blair HC $2010 \mathrm{ACTH}$ is a novel regulator of bone mass. Annals of the New York Academy of Sciences 1192 110-116. (doi:10.1111/ j.1749-6632.2009.05231.x)

Jernas M, Palming J, Sjoholm K, Jennische E, Svensson PA, Gabrielsson BG, Levin M, Sjogren A, Rudemo M, Lystig TC et al. 2006 Separation of human adipocytes by size: hypertrophic fat cells display distinct gene expression. FASEB Journal 20 1540-1542. (doi:10.1096/fj.05-5678fje)

Knopp RH, Paramsothy P, Retzlaff BM, Fish B, Walden C, Dowdy A, Tsunehara C, Aikawa K \& Cheung MC 2005 Gender differences in lipoprotein metabolism and dietary response: basis in hormonal differences and implications for cardiovascular disease. Current Atherosclerosis Reports 7 472-479. (doi:10.1007/s11883-005-0065-6)

Komori T 2013 Functions of the osteocyte network in the regulation of bone mass. Cell and Tissue Research 352 191-198. (doi:10.1007/s00441012-1546-x)

Landschulz KT, Pathak RK, Rigotti A, Krieger M \& Hobbs HH 1996 Regulation of scavenger receptor, class B, type I, a high density lipoprotein receptor, in liver and steroidogenic tissues of the rat. Journal of Clinical Investigation 98 984-995. (doi:10.1172/JCI118883)

Leidig-Bruckner G \& Ziegler R 2001 Diabetes mellitus a risk for osteoporosis? Experimental and Clinical Endocrinology \& Diabetes 109(Suppl 2) S493-S514. (doi:10.1055/s-2001-18605)

Le Lay S, Krief S, Farnier C, Lefrere I, Le Liepvre X, Bazin R, Ferre P \& Dugail I 2001 Cholesterol, a cell size-dependent signal that regulates glucose metabolism and gene expression in adipocytes. Journal of Biological Chemistry 276 16904-16910. (doi:10.1074/jbc.M010955200) 
Li XF, Yan J, Jiang LS \& Dai LY 2011 Age-related variations of leptin receptor expression in the growth plate of spine and limb: gender- and regionspecific changes. Histochemistry and Cell Biology 135 487-497. (doi:10.1007/s00418-011-0805-3)

Lopez D \& McLean MP 2006 Estrogen regulation of the scavenger receptor class B gene: anti-atherogenic or steroidogenic, is there a priority? Molecular and Cellular Endocrinology 247 22-33. (doi:10.1016/j.mce. 2005.10.005)

Lundasen T, Liao W, Angelin B \& Rudling M 2003 Leptin induces the hepatic high density lipoprotein receptor scavenger receptor B type I (SR-BI) but not cholesterol $7 \alpha$-hydroxylase (Cyp7a1) in leptin-deficient $(o b / o b)$ mice. Journal of Biological Chemistry 278 43224-43228. (doi:10.1074/jbc.M302645200)

Martin SS, Qasim A \& Reilly MP 2008 Leptin resistance: a possible interface of inflammation and metabolism in obesity-related cardiovascular disease. Journal of the American College of Cardiology 52 1201-1210. (doi:10.1016/j.jacc.2008.05.060)

Martineau C, Martin-Falstrault L, Brissette L \& Moreau R 2014 The atherogenic Scarb1 null mouse model shows a high bone mass phenotype. American Journal of Physiology. Endocrinology and Metabolism 306 E48-E57. (doi:10.1152/ajpendo.00421.2013)

Mattsson C \& Olsson T 2007 Estrogens and glucocorticoid hormones in adipose tissue metabolism. Current Medicinal Chemistry 14 2918-2924. (doi:10.2174/092986707782359972)

Miettinen HE, Rayburn H \& Krieger M 2001 Abnormal lipoprotein metabolism and reversible female infertility in HDL receptor (SR-BI)deficient mice. Journal of Clinical Investigation 108 1717-1722. (doi:10.1172/JCI13288)

Mitchell BD \& Yerges-Armstrong LM 2011 The genetics of bone loss: challenges and prospects. Journal of Clinical Endocrinology and Metabolism 96 1258-1268. (doi:10.1210/jc.2010-2865)

Motyl KJ \& Rosen CJ 2012 Understanding leptin-dependent regulation of skeletal homeostasis. Biochimie 94 2089-2096. (doi:10.1016/j.biochi. 2012.04.015)

Orozco P 2004 Atherogenic lipid profile and elevated lipoprotein (a) are associated with lower bone mineral density in early postmenopausal overweight women. European Journal of Epidemiology 19 1105-1112. (doi:10.1007/s10654-004-1706-8)

Poli A, Bruschi F, Cesana B, Rossi M, Paoletti R \& Crosignani PG 2003 Plasma low-density lipoprotein cholesterol and bone mass densitometry in postmenopausal women. Obstetrics and Gynecology 102 922-926. (doi:10.1016/j.obstetgynecol.2003.07.004)

Raisz LG 2005 Pathogenesis of osteoporosis: concepts, conflicts, and prospects. Journal of Clinical Investigation 115 3318-3325. (doi:10.1172/ JCI27071)

von der Recke P, Hansen MA \& Hassager C 1999 The association between low bone mass at the menopause and cardiovascular mortality. American Journal of Medicine 106 273-278. (doi:10.1016/S00029343(99)00028-5)

Rigotti A, Trigatti BL, Penman M, Rayburn H, Herz J \& Krieger M 1997 A targeted mutation in the murine gene encoding the high density lipoprotein (HDL) receptor scavenger receptor class B type I reveals its key role in HDL metabolism. PNAS 94 12610-12615. (doi:10.1073/ pnas.94.23.12610)

Rigotti A, Miettinen HE \& Krieger M 2003 The role of the high-density lipoprotein receptor SR-BI in the lipid metabolism of endocrine and other tissues. Endocrine Reviews 24 357-387. (doi:10.1210/er.2001-0037)

Rizzoli R, Bonjour JP \& Ferrari SL 2001 Osteoporosis, genetics and hormones. Journal of Molecular Endocrinology 26 79-94. (doi:10.1677/ jme.0.0260079)
Silver DL, Jiang XC \& Tall AR 1999 Increased high density lipoprotein (HDL), defective hepatic catabolism of ApoA-I and ApoA-II, and decreased ApoA-I mRNA in $o b / o b$ mice. Possible role of leptin in stimulation of HDL turnover. Journal of Biological Chemistry $\mathbf{2 7 4}$ 4140-4146. (doi:10.1074/jbc.274.7.4140)

Silver DL, Wang N \& Tall AR 2000 Defective HDL particle uptake in $o b / o b$ hepatocytes causes decreased recycling, degradation, and selective lipid uptake. Journal of Clinical Investigation 105 151-159. (doi:10.1172/ JCI8087)

Stagi S, Cavalli L, Iurato C, Seminara S, Brandi ML \& de Martino M 2013 Bone metabolism in children and adolescents: main characteristics of the determinants of peak bone mass. Clinical Cases in Mineral and Bone Metabolism 10 172-179.

Stojanovic OI, Lazovic M, Lazovic M \& Vuceljic M 2011 Association between atherosclerosis and osteoporosis, the role of vitamin D. Archives of Medical Science 7 179-188. (doi:10.5114/aoms.2011.22066)

Sun Y, Wang N \& Tall AR 1999 Regulation of adrenal scavenger receptor-BI expression by ACTH and cellular cholesterol pools. Journal of Lipid Research 40 1799-1805.

Sweet MG, Sweet JM, Jeremiah MP \& Galazka SS 2009 Diagnosis and treatment of osteoporosis. American Family Physician 79 193-200.

Thomas T, Burguera B, Melton LJ III, Atkinson EJ, O'Fallon WM, Riggs BL \& Khosla S 2001 Role of serum leptin, insulin, and estrogen levels as potential mediators of the relationship between fat mass and bone mineral density in men versus women. Bone 29 114-120. (doi:10.1016/ S8756-3282(01)00487-2)

Tondu AL, Robichon C, Yvan-Charvet L, Donne N, Le Liepvre X, Hajduch E, Ferre P, Dugail I \& Dagher G 2005 Insulin and angiotensin II induce the translocation of scavenger receptor class B, type I from intracellular sites to the plasma membrane of adipocytes. Journal of Biological Chemistry 280 33536-33540. (doi:10.1074/jbc.M502392200)

Turner RT, Kalra SP, Wong CP, Philbrick KA, Lindenmaier LB, Boghossian S \& Iwaniec UT 2013 Peripheral leptin regulates bone formation. Journal of Bone and Mineral Research 28 22-34. (doi:10.1002/jbmr.1734)

Uyama O, Yoshimoto Y, Yamamoto Y \& Kawai A 1997 Bone changes and carotid atherosclerosis in postmenopausal women. Stroke $\mathbf{2 8}$ 1730-1732. (doi:10.1161/01.STR.28.9.1730)

van der Velde AE \& Groen AK 2005 Shifting gears: liver SR-BI drives reverse cholesterol transport in macrophages. Journal of Clinical Investigation 115 2699-2701. (doi:10.1172/JCI26241)

Wang X, Rundle CH, Wergedal JE, Srivastava AK, Mohan S \& Lau KH 2007 Loss of sex-specific difference in femoral bone parameters in male leptin knockout mice. Calcified Tissue International 80 374-382. (doi:10.1007/ s00223-007-9026-0)

Weiss LA, Barrett-Connor E, von Muhlen D \& Clark P 2006 Leptin predicts $\mathrm{BMD}$ and bone resorption in older women but not older men: the Rancho Bernardo study. Journal of Bone and Mineral Research 21 758-764. (doi:10.1359/jbmr.060206)

Yamaguchi T, Sugimoto T, Yano S, Yamauchi M, Sowa H, Chen Q \& Chihara K 2002 Plasma lipids and osteoporosis in postmenopausal women. Endocrine Journal 49 211-217. (doi:10.1507/endocrj.49.211)

Yu BL, Zhao SP \& Hu JR 2010 Cholesterol imbalance in adipocytes: a possible mechanism of adipocytes dysfunction in obesity. Obesity Reviews 11 560-567. (doi:10.1111/j.1467-789X.2009.00699.x)

Zhou Z, Neupane M, Zhou HR, Wu D, Chang CC, Moustaid-Moussa N \& Claycombe KJ 2012 Leptin differentially regulate STAT3 activation in $o b / o b$ mouse adipose mesenchymal stem cells. Nutrition and Metabolism 9 109. (doi:10.1186/1743-7075-9-109)

Received in final form 6 June 2014

Accepted 11 June 2014

Accepted Preprint published online 13 June 2014 http://joe.endocrinology-journals.org DOI: 10.1530/JOE-14-0147
() 2014 Society for Endocrinology Printed in Great Britain
Published by Bioscientifica Ltd. 